\title{
Penetrance of phaeochromocytoma in RET G533C carriers differs between South America and Europe
}

\section{Dear Editor,}

In a recent issue of Endocrine-Related Cancer, Castinetti et al. reported a different natural history of phaeochromocytoma in multiple endocrine neoplasia type 2 (MEN 2) patients between Europe and South America (Castinetti et al. 2017). The authors retrospectively collected data about the phaeochromocytoma in MEN 2 patients carrying RET mutations on exons 10 and 11 in 14 countries from South America, Southern Europe, Western Europe and Central Europe. They showed that phaeochromocytoma penetrance is lower (53\%) in South America compared to South Europe, Western Europe and Central Europe (75-81\%). Furthermore, there was a different significance for unilateral and bilateral phaeochromocytoma penetrance between South America and the other three areas. Nearly $50 \%$ of the Central Europe patients will have a phaeochromocytoma by the age of 33 years, while the same percent will have a phaeochromocytoma by the age of 43 years in South America. The delay was even higher for bilateral phaeochromocytoma in Europe vs South America. The authors suggested that RET mutation is not the only determinant of the penetrance of phaeochromocytoma and that its natural history could be influenced by genetic or environmental factors.

As we understand that these findings are of clinical importance, we sought to verify whether genetic or environmental factors might have a modifying effect on the disease penetrance for other RET mutations. We retrospectively reviewed the published data on 183 patients carrying RET G533C mutation on exon 8 in South America (Brazil) and Europe (Greece and Ireland). This rare mutation was first reported in a Brazilian family of Caucasian origin with ancestors from Catalunia, Spain, who immigrated to Brazil at the end of the 19th century (Da Silva et al. 2003, Oliveira et al. 2011, Signorini et al. 2014). To date, this is the largest reported family with a
RET mutation and MEN 2A, whose family members have been followed for over 15 years. Four hundred and thirty two of 728 recruited relatives were genetically tested for the RET G533C mutation, 119 being G533C carriers. At the last follow-up, the median age of the 60 G533C carriers who underwent thyroidectomy was 45 years (ranges 6-75 years) and the mean age of the 59 patients awaiting surgery was 17 years (ranges $4-39$ years). Among all patients who underwent surgery, 46 patients had medullary thyroid carcinoma, 11 patients had C-cell hyperplasia and 1 patient had phaeochromocytoma (Da Silva et al. 2003, Oliveira et al. 2011, Signorini et al. 2014). During this long-term follow-up (mean follow-up period of 12.9), genetic and clinical characteristics of these patients have been described in detail (Oliveira et al. 2011, Signorini et al. 2014). Importantly, the large majority $(43 / 46 ; 93 \%)$ of the patients who underwent surgery and were diagnosed with medullary thyroid carcinoma are over the age of 30 years, which is the youngest age reported in a patient with phaeochromocytoma in Greece.

In 2007, Kaldrymides et al. reported a Greek patient with MEN 2A harbouring the same RET G533C mutation (5), followed by other reports (Kaldrymides et al. 2006, Bethanis et al. 2007). Interestingly, in three Greek families, phaeochromocytoma was the first clinical manifestation (Bethanis et al. 2007, Peppa et al. 2008). A few years later, Sarika et al. identified the G533C mutation in 11 families with MEN 2 in Greece. Phaeochromocytoma was described as the first clinical manifestation in one of these families. The authors also identified G533C mutation in ten cases with apparently sporadic medullary thyroid carcinoma (Sarika et al. 2012, 2015). In 2013, Castro et al. published the first RET 533 family from the United States, with ancestors from Greece, presenting with MEN 2A in several affected members 
Table 1 Prevalence of phaeochromocytoma in RET G533C carriers in two continents.

\begin{tabular}{lcc}
\hline Total individuals screened for RET mutation & South America* \\
\# of RET G533C carriers & 432 \\
\# cases of MTC & $119 / 432(27.5 \%)$ \\
\# cases of phaeochromocytoma & $46 / 119(38.6 \%)$ \\
Mean age at diagnosis in years (range) & $1 / 119(0.84 \%)$ \\
Unilateral & $63^{\ddagger}$ \\
Bilateral & $1 / 1(100 \%)$ \\
Initial manifestation & $0 / 1(0 \%)$ \\
\end{tabular}

\begin{tabular}{c}
\hline Europe (Greece)** \\
\hline $222 \S$ \\
$64 / 222(28.8 \%)$ \\
$34 / 64(53.1 \%)$ \\
$6 / 64(9.4 \%)$ \\
$43.5(30-66)$ \\
$4 / 6(66.7 \%)$ \\
$2 / 6(33.3 \%)$ \\
$5 / 6(83.3 \%)$ \\
\hline
\end{tabular}

\begin{tabular}{c}
\hline $\boldsymbol{P}$ value \\
\hline- \\
$\mathrm{ns}$ \\
$\mathrm{ns}$ \\
0.0079 \\
- \\
$\mathrm{ns}$ \\
$\mathrm{ns}$ \\
$\mathrm{ns}$
\end{tabular}

*Da Silva et al. (2003), Signorini et al. (2014); **Kaldrymes et al. (2006), Bethanis et al. (2007), Peppa et al. (2008), Sarika et al. (2012, 2015); sincluding 129 sporadic cases; ₹only one phaeochromocytoma case was described among 119 carriers.

ns, not significant.

(Castro et al. 2013). Remarkably, not only the prevalence of phaeochromocytoma in this family was higher than the prevalence previously reported in Brazil, but also three patients presented with phaeochromocytoma as their initial manifestation. Finally, Casey et al. reported a case in Ireland of MEN 2A and RET G533C mutation diagnosed with phaeochromocytoma as the first clinical manifestation (Casey et al. 2013). Even if there were variances in screening methods, the evident difference observed in the initial presentation of the disease is remarkable.

Until now, these are the only studies that report G533C mutation on RET gene in MEN 2 families or apparently sporadic medullary thyroid carcinoma cases. Although it has been reported that G533C was identified in one family in South Portugal and a few families in France (Sarika et al. 2015), no information is available in the literature. As far as we know, there is no other kindred with RET G533C mutation in the United States (John C Morris and Samuel Wells, personal communications).

In this study, we observed a significant difference in the prevalence of phaeochromocytoma in patients from South America when compared to Europe $(P=0.0079)$ (Table 1$)$. Notably, the primary ancestors of both South American and Europe populations were from Greece. Moreover, in Europe and North America, the phaeochromocytoma was the first clinical manifestation in most families, whereas in South America, phaeochromocytoma was diagnosed 5 years after the diagnosis of medullary thyroid carcinoma. Actually, the median age at diagnosis in Europe was 43.5 years, while in South America, the patient has presented with phaeochromocytoma at the age of 63 years (Table 1). Moreover, logistic regression analysis showed that the chance of having a phaeochromocytoma in a Greek family, compared to the Brazilian family, was $12.2(P=0.022)$, 95\% CI (1.4-103.8) (IBM Corp, Released 2017: IBM SPSS Statistics for Windows, version 25.0). Therefore, this analysis suggests that the risk for phaeochromocytoma development in patients with RET G533C mutation could also be affected by additional mutations or polymorphism within RET gene or in other genes or even environmental factors (modifying factors).

In summary, similar to those reported by Castinetti et al., our results highlight the fact that RET germline mutation may not be the only determinant of the natural history of phaeochromocytoma in MEN 2 patients with G533C, particularly after our recent data suggesting that Brazilian and Greek patients carrying the same RET G533C mutation originate from a common ancestor (Cunha et al. 2017, Machens et al. 2018).

Rui M B Maciel ${ }^{1}$

Larissa $\mathrm{V} \mathrm{Bim}{ }^{2}$

Cleber P Camacho ${ }^{1}$

Janete M Cerutti2

${ }^{1}$ Division of Endocrinology, Department of Medicine, Universidade Federal de São Paulo Escola Paulista de Medicina, São Paulo, São Paulo, Brazil

${ }^{2}$ Division of Genetics, Department of Morphology and Genetics, Universidade Federal de São Paulo Escola Paulista de Medicina, São Paulo, São Paulo, Brazil

Correspondence should be addressed to J M Cerutti: j.cerutti@unifesp.br

\section{Declaration of interest}

The authors declare that there is no conflict of interest that could be perceived as prejudicing the impartiality of this article.

\section{Funding}

The study was supported by research grant number 2014/06570-6 from the Fundação de Amparo a Pesquisa do Estado de São Paulo (FAPESP) and grant 470441/2013-5 from the Conselho Nacional de Desenvolvimento Científico e Tecnológico (CNPq). J M C is a recipient of a scholarship of Research Productivity from CNPq. 


\section{Acknowledgments}

The authors would like to thank $\mathrm{Dr}$ John C Morris (Division of Endocrinology, Mayo Clinic, Rochester, USA) and Dr Samuel Wells (Cancer Genetics Branch, National Cancer Institute, NIH, Bethesda) for the personal communications about RET G533C mutations data in the USA population.

\section{References}

Bethanis S, Koutsodontis G, Palouka T, Avgoustis C, Yannoukakos D, Bei T, Papadopoulos S, Linos D \& Tsagarakis S 2007 A newly detected mutation of the RET protooncogene in exon 8 as a cause of multiple endocrine neoplasia type 2A. Hormones 6 152-156. (https://doi. org/10.14310/horm.2002.1111011)

Castinetti F, Maia AL, Peczkowska M, Barontini M, Hasse-Lazar K, Links TP, Toledo RA, Dvorakova S, Mian C, Bugalho MJ, et al. 2017 The penetrance of men2 pheochromocytoma is not only determined by ret mutations. Endocrine-Related Cancer 24 L63-L67. (https://doi. org/10.1530/ERC-17-0189)

Castro MR, Thomas BC, Richards ML, Zhang J \& Morris JC 2013 Multiple endocrine neoplasia type 2A due to an exon 8 (G533C) mutation in a large North American kindred. Thyroid 23 1547-1552. (https://doi.org/10.1089/thy.2012.0599)

Casey R, Prendeville S, Joyce C \& O'Halloran D 2013 First reported case in Ireland of MEN2A due to a rare mutation in exon 8 of the RET oncogene. Endocrinolology Diabetes and Metabolism Case Reports 2013 130044. (https://doi.org/10.1530/EDM-13-0044)

Cunha LL, Lindsey SC, França MIC, Sarika L, Papathoma A, Kunii IS, Cerutti JM, Dias-da-Silva MR, Alevizaki M \& Maciel RMB 2017 Evidence for the founder effect of RET533 as the common Greek and Brazilian ancestor spreading multiple endocrine neoplasia 2A. European Journal of Endocrinology 176 515-519. (https://doi. org/10.1530/EJE-16-1021)

Da Silva AM, Maciel RM, Da Silva MR, Toledo SR, De Carvalho MB \& Cerutti JM 2003 A novel germ-line point mutation in RET exon 8 (Gly(533)Cys) in a large kindred with familial medullary thyroid carcinoma. Journal of Clinical Endocrinology and Metabolism $\mathbf{8 8}$ 5438-5443. (https://doi.org/10.1210/jc.2003-030997)
Kaldrymides P, Mytakidis N, Anagnostopoulos T, Vassilou M, Terpiti A, Zahariou M, Rampias T, Koutsodontis G, Konstantopoulou I, Ladopoulou A, et al. 2006 A rare RET gene exon 8 mutation is found in two Greek kindreds with familial medullary thyroid carcinoma implications for screening. Clinical Endocrinology 64 561-566. (https://doi. org/10.1111/j.1365-2265.2006.02509)

Machens A, Lorenz K, Weber F \& Dralle H 2018 Geographic epidemiology of medullary thyroid cancer families: unearthing European ancestral heritage. Endocrine-Related Cancer 25 L27-L30. (https://doi.org/10.1530/ERC-17-0514)

Oliveira MN, Hemerly JP, Bastos AU, Tamanaha R, Latini FR, Camacho CP, Impellizzeri A, Maciel RM \& Cerutti JM 2011 The RET p.G533C mutation confers predisposition to multiple endocrine neoplasia type $2 \mathrm{~A}$ in a Brazilian kindred and is able to induce a malignant phenotype in vitro and in vivo. Thyroid 21 975-985. (https://doi.org/10.1089/thy.2010.0190)

Peppa M, Boutati E, Kamakari S, Pikounis V, Peros G, Panayiotides IG, Economopoulos T, Raptis SA \& Hadjidakis D 2008 Multiple endocrine neoplasia type $2 \mathrm{~A}$ in two families with the familial medullary thyroid carcinoma associated G533C mutation of the RET proto-oncogene. European Journal of Endocrinology 159 767-771. (https://doi.org/10.1530/EJE-08-0476)

Sarika HL, Papathoma A, Garofalaki M, Vasileiou V, Vlassopoulou B, Anastasiou E \& Alevizaki M. 2012 High prevalence of exon 8 G533C mutation in apparently sporadic medullary thyroid carcinoma in Greece. Clinical Endocrinology 77 857-862. (https://doi. $\operatorname{org} / 10.1111 /$ j.1365-2265.2012.04462)

Sarika HL, Papathoma A, Garofalaki M, Saltiki K, Pappa T, PazaitouPanayiotou K, Anastasiou E \& Alevizaki M 2015 Genetic screening of patients with medullary thyroid cancer in a referral center in Greece during the past two decades. European Journal of Endocrinology 172 501-509. (https://doi.org/10.1530/EJE-14-0817)

Signorini PS, Franca MI, Camacho CP, Lindsey SC, Valente FO, Kasamatsu TS, Machado AL, Salim CP, Delcelo R, Hoff AO, et al. 2014 A ten-year clinical update of a large RET p.Gly533Cys kindred with medullary thyroid carcinoma emphasizes the need for an individualized assessment of affected relatives. Clinical Endocrinology 80 235-245. (https://doi.org/10.1111/cen.12264)

Received in final form 14 May 2018

Accepted 17 May 2018 (c) 2018 Society for Endocrinology Published by Bioscientifica Ltd. Printed in Great Britain 